Research Article

\title{
Beam Steerable and Frequency Reconfigurable Antenna Array for 5G Mobile Networks
}

\author{
Muhammad Farooq, Shahid Bashir* and Salman Ilahi Siddiqui
}

Department of Electrical Engineering, University of Engineering and Technology, Peshawar, Khyber Pakhtunkhwa, Pakistan.

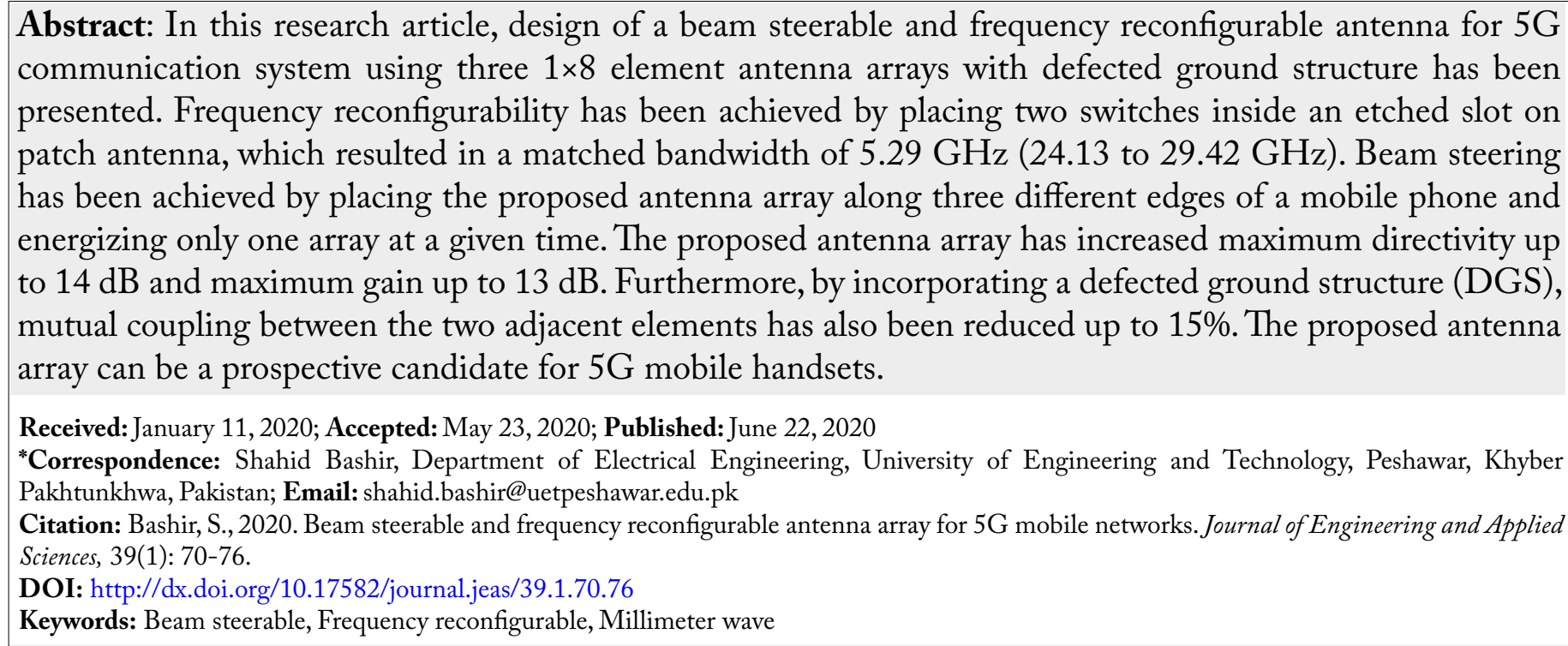

\section{Introduction}

$\mathrm{T}$ he era of mobile communication has been divided into different generations each adding extra functionalities to our mobile phones; the first generation $(1 \mathrm{G})$ was based on voice communication, second generation $(2 \mathrm{G})$ added the feature of text messaging, third generation $(3 \mathrm{G})$ introduced data communication and fourth generation (4G) improved the data rates (Ezhilarasan and Dinakaran, 2017). Nowadays, research is being carried out in the area of Internet of things (IoT) as we are progressing towards the automation of domestic, commercial and industrial appliances and systems. Io $\mathrm{T}$ will enable us to remotely access and control them (Agiwal et al., 2019; Sirinivasan et al., 2019).

In the near future, it is being planned to provide fast Internet connection to large number of devices per square kilometer of area. Due to high data rate requirement of users, fifth generation $(5 \mathrm{G})$ technology is now under development. Using $5 \mathrm{G}$ technology, users will be given higher bandwidth in order to increase the speed of communication (Hossain and Hasan, 2015). $5 \mathrm{G}$ provides a higher level of performance as compared to the previous generations by offering high speed connectivity, enormous data handling capacity, low latency and much more. $5^{\text {th }}$ generation system faces problems relating to small cell sizes and higher propagation loss. In order to solve these problems a huge number of base stations will be needed. Further, antenna should have the capability of steering its main beam towards the user in order to avoid interference.

$5 \mathrm{G}$ technology will use millimeter wave band because the bands (under $6 \mathrm{GHz}$ ) which are so far utilized for $2 \mathrm{G}, 3 \mathrm{G}$, and $4 \mathrm{G}$ are not enough to provide such high data rates (Agiwal et al., 2016; Niu et al., 2015). 
In millimeter wave band, frequency is very high as compared to the previously used frequency bands. The path loss in free space can be expressed as follows (Aragon and Alejandro, 2008).

$$
L_{F(d B)}=32.4+20 \log R+20 \log f_{M H z}
$$

In Equation $1 L_{F(d b)}$ represents path loss in $\mathrm{dB}, R$ represents the distance between sender and receiver and $f_{M H Z}$ represents frequency in $\mathrm{MHz}$. From Equation 1 , it is clear that by increasing frequency, there will be an increase in path loss. In this research study, we have considered $26 \mathrm{GHz}$ for communication, so free space path loss will be very high which means that the signal strength will rapidly decrease as signal moves from transmitter towards receiver (Rappaport et al., 2013). In order to overcome such high attenuation, large number of base stations will be installed and there will be very small distance between them, i.e., the cell size will be small (Hur et al., 2013). Because of small cell size, mobile phone antenna will be doing frequent handovers towards the best base station while moving. In order to make it possible, antenna installed in mobile phone should be capable to steer its main beam towards any required direction (Han et al., 2015). Mobile phone antenna should also be capable to have high gain in the desired direction of radiation to overcome high attenuation (Agiwal et al., 2019). Furthermore, the antenna should be capable to cover larger bandwidth for providing high data rates to the users (Agiwal et al., 2019; Abirami, 2017).

There are a number of methods so far utilized for achieving beam steering. One of the beam steerable antennas is presented in (Zhang et al., 2017). This antenna has four L-shaped microstrips. A vertical probe is provided to energize each of L-shaped mictrostrip. Between these microstrips, Electromagnetic Band Gap (EBG) is also used for increasing the gain. Beam steering can be achieved by turning $\mathrm{ON}$ different ports. Bandwidth and gain of this antenna ware not suitable for $5 \mathrm{G}$ application.

A simple beam steerable antenna is also presented in (Nayak et al., 2012). This antenna consists of five patches and switches. One of these patches is the main patch and other four surround it which are connected with the main patch using switches. Different radiation patterns can be achieved by different combinations of switches. Further, the gain obtained was good, but bandwidth was very low.
A beam steerable antenna which is energized using capacitive coupled feeding is given in ( $\mathrm{Pal}$ et al., 2014). Their proposed antenna has a shape of square and a port is connected to each side of that square. By exciting one of these ports and keeping other OFF, we can have main beam in different directions. It was a good option for sub $6 \mathrm{GHz}$ band.

For obtaining frequency reconfiguration different methods are proposed in literature. Use of PIN diodes along with parasitic elements is proposed in (Baruah and Bhattacharyya, 2017; Varsha and Sumi, 2016). In (Zadehparizi and Jam, 2018) and (Ikram et al., 2019) reconfigurable antennas are presented. These antennas have slots in ground plane in which switches were installed. By turning these switches $\mathrm{ON}$ and $\mathrm{OFF}$ resonance frequency can be changed.

A frequency reconfigurable antenna having $Z$ shape slot and switches installed in the ground plane is proposed in (Jenath and Nagarajan, 2017). Different resonance frequencies can be achieved by having different switch combinations. Most of these existing methods require large print area, which is usually not available in typical mobile phone.

In this research work, we propose a novel three arrays configuration. Each array having a width of $3.8 \mathrm{~mm}$, is composed of eight radiating elements. Due to small width, array can be adjusted at mobile phone's edge. The use of eight elements has increased the directivity up to $14 \mathrm{~dB}$. Each antenna array is installed at different locations inside a mobile phone. At a given time, only one array is energized and thus a particular direction is covered using beam steering. For overcoming mutual coupling between antenna elements, we have used defected ground structure (DGS) (Wei et al., 2016; Salgare et al., 2015).

For covering large bandwidth, we have used the concept of frequency reconfigurability. We have inserted a slot in each element. In that slot we have used two switches. By turning these switches $\mathrm{ON}$ and $\mathrm{OFF}$, electrical length of the element changes and thus the resonance frequency varies. Using this technique, we have covered a band of $24.11 \mathrm{GHz}$ to $29.30 \mathrm{GHz}$ containing 3 resonant frequencies that can be selected at different switch combinations.

\section{Antenna design}

Antenna element: The proposed antenna element is 
shown in Figure 1. It consists of a metallic patch with $T$ shaped slot. Inside $T$ slot there is a narrow metallic strip. Coaxial cable is connected to this inner strip to feed the antenna element. Such a capacitive feeding provides a large reduction in the size of the antenna. In order to cover the entire surface area of the patch charges will flow through the edges, so the electrical size of the antenna is greater whereas the physical size is smaller. FR-4 dielectric material with $\varepsilon r=4.3$ and $0.8 \mathrm{~mm}$ thickness was used as substrate. Complete dimensions of the proposed antenna element are given below:

$\mathrm{Lg}=3.8 \mathrm{~mm}, \mathrm{Wg}=6 \mathrm{~mm}, \mathrm{Lp} 1=1 \mathrm{~mm}, \mathrm{Wp} 1=0.3$ $\mathrm{mm}, \mathrm{fv}=0.2 \mathrm{~mm}, \mathrm{Lp} 2=1.75 \mathrm{~mm}, \mathrm{Wp} 2=2.5 \mathrm{~mm}$, Lslot $1=2.4 \mathrm{~mm}$, Wslot $1=0.3 \mathrm{~mm}$, Lslot $2=1 \mathrm{~mm}$, Wslot $2=0.5 \mathrm{~mm}, \mathrm{t}=0.01 \mathrm{~mm}, \mathrm{~h}=0.8 \mathrm{~mm}$.

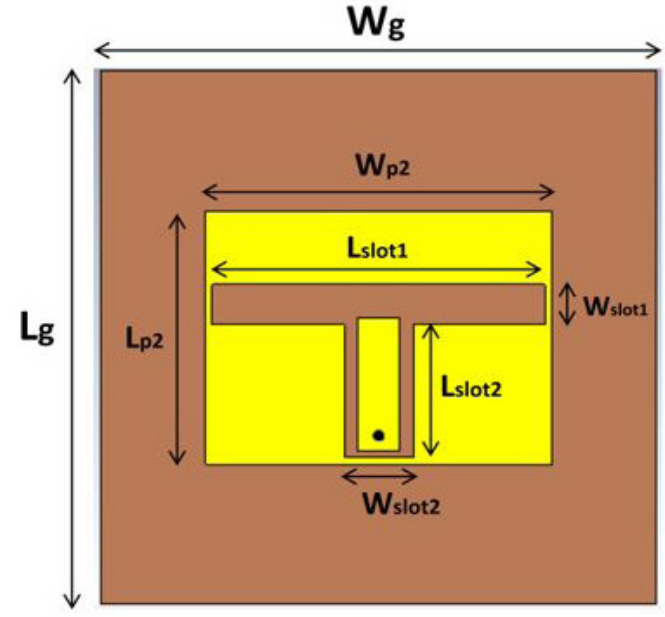

(a)

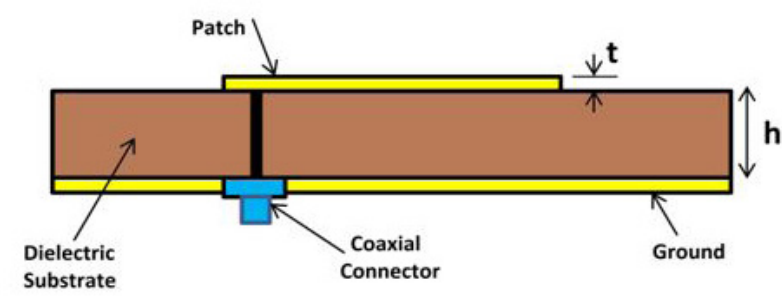

(c)

Figure 1: Proposed Antenna element. (a) Front view of antenna element (b) Inner patch of antenna element (c) Side view of antenna element.

In order to cover a larger bandwidth, two switches (e.g., RF MEMS switches) are placed within T slot as shown in Figure 2. Turning these switches ON, will provide shorter path for the flow of charges to cover the whole surface and thus electrical size of the element will reduce and resonance frequency will increase. In this way we can cover a larger band.

Antenna array: The single element was then used to model 1x8 element array as shown in Figure 3. Three such arrays were then positioned perpendicular to each other as shown in Figure 4. One of the arrays can be energized at a given time, resulting in radiation patterns in three different directions.

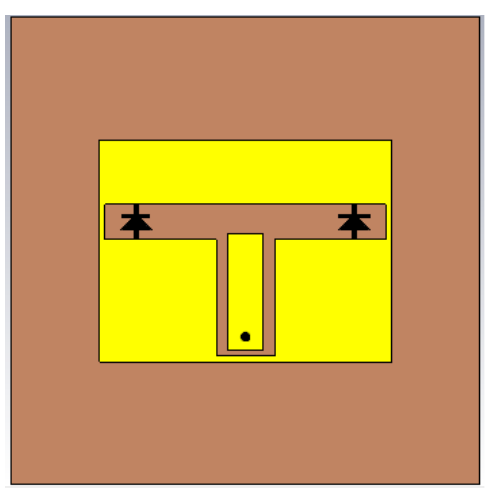

Figure 2: Antenna element with switches.

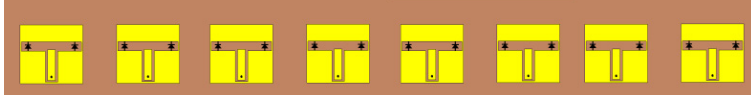

Figure 3: $1 \times 8$ element array

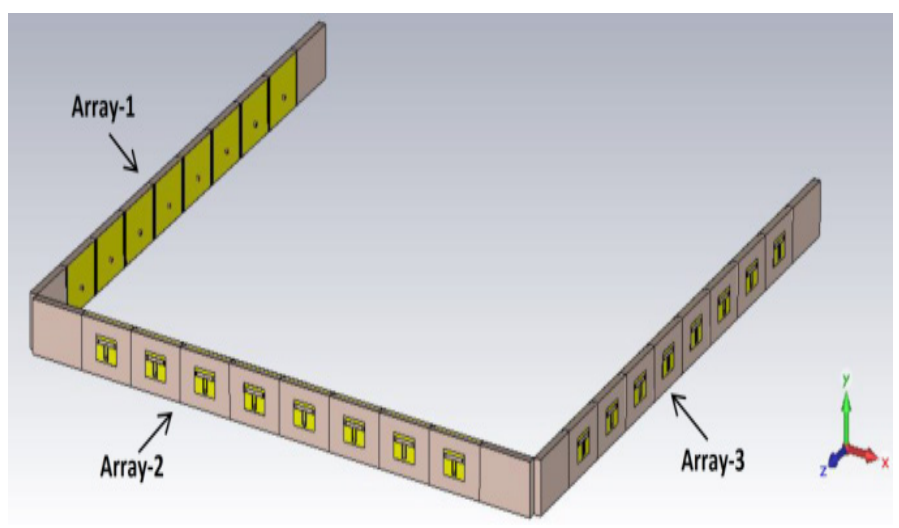

Figure 4: Proposed beam steering antenna array.

The proposed antenna array can be fabricated along the edges of a typical mobile set due to its small width of $3.8 \mathrm{~mm}$ as shown in Figure 5.

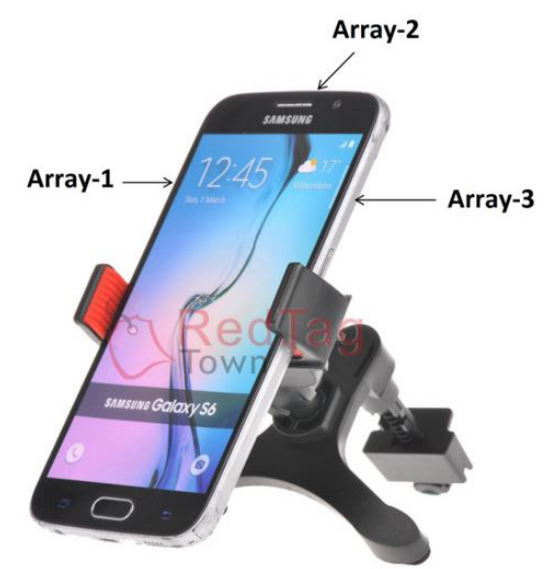

Figure 5: Prospective position of proposed array in typical mobile phone. 
Defected ground structure: In order to minimize the mutual coupling issues of typical antenna array different techniques were used in the recent work (Ojaroudi-Parchin et al., 2020). Here defected ground structure (DGS) was employed in the ground plane as surface wave filter to reduce mutual coupling (Khandelwal et al., 2017). In Figure 6, portion of DGS is shown with Lgslot $=3.79 \mathrm{~mm}$ and Wgslot $=0.1 \mathrm{~mm}$. These values have been selected after parameterization and optimization in CST MWS.

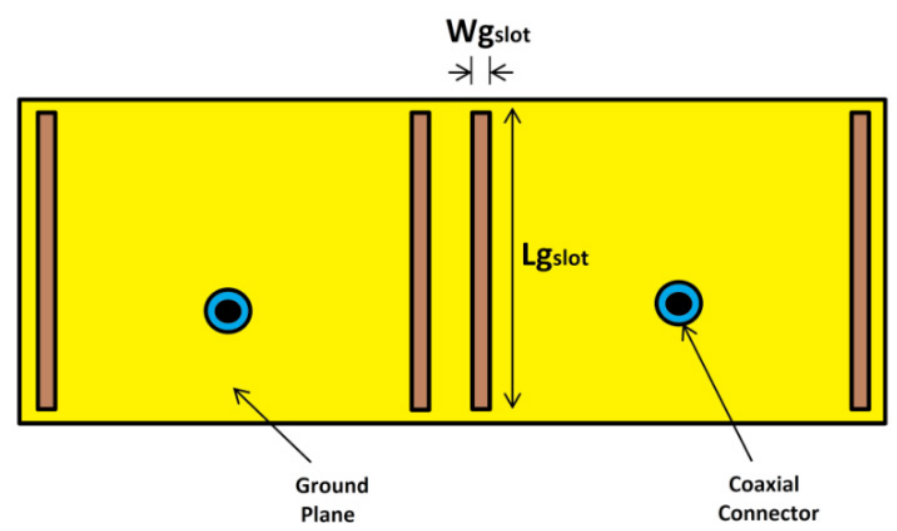

Figure 6: DGS at the ground plane between two elements.

\section{Results and Discussion}

The single element was simulated in CST MWS for different switch combinations and its combined return loss is given in Figure 7. It shows that using frequency reconfigurability, bandwidth of $5.1 \mathrm{GHz}$ ( 24.3 to $29.49 \mathrm{GHz}$ ) can be achieved using this single element.

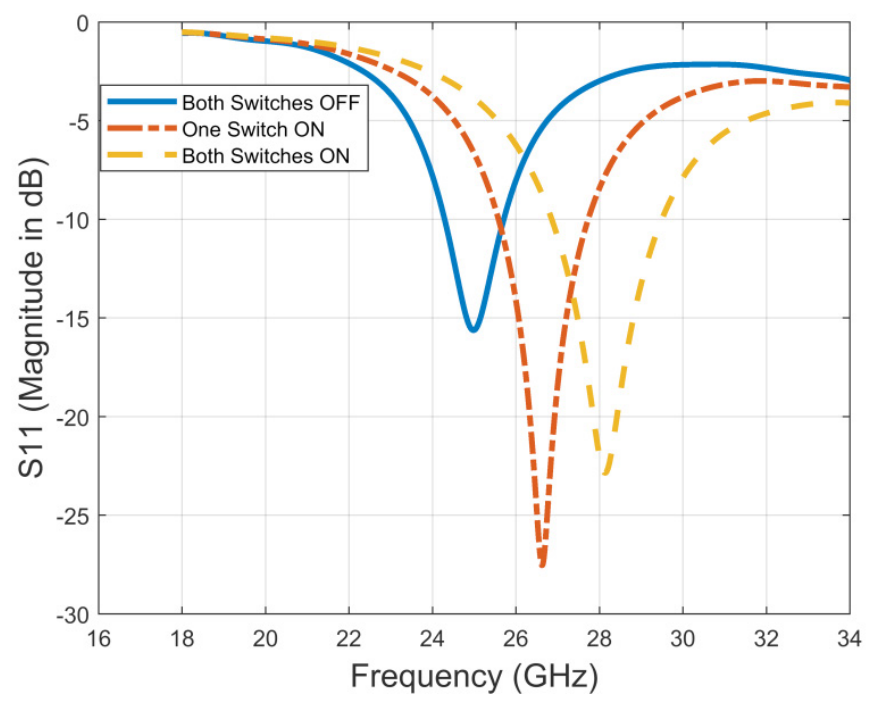

Figure 7: Return loss of single element.

The simulated return loss of $1 \mathrm{x} 8$ element array is shown in Figure 8, for three different switch combinations (i.e., both switches OFF, only one switch ON, both switches ON). It is clear that a total bandwidth of 5.29 GHz (i.e., 24.13 to $29.42 \mathrm{GHz}$ ) can be obtained with the help of frequency reconfiguration.

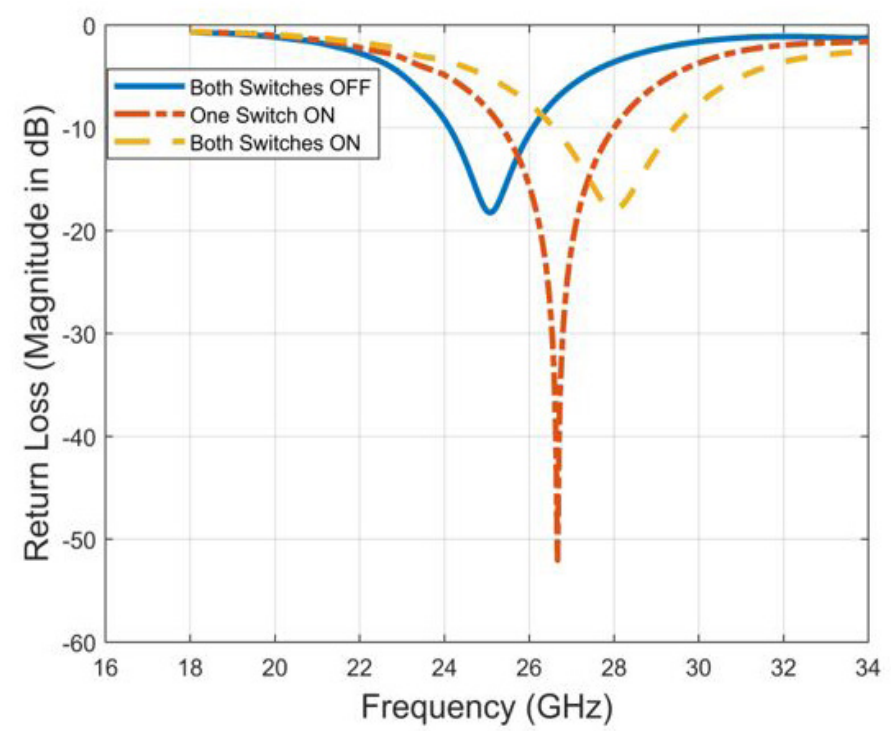

Figure 8: Return loss for the proposed antenna.

In order to reduce mutual coupling between adjacent array elements, we have used DGS between each two elements. It acts as a filter and suppresses surface waves. For comparing the performance of DGS, we simulated two element array with and without DGS. An improvement of $6.45 \%$ in $\mathrm{S} 12$ is obtained at resonant frequency of $25.2 \mathrm{GHz}$ when both switches are $\mathrm{OFF}$ as shown in Figure 9. Figure 10 shows an improvement of $8.89 \%$ in $\mathrm{S} 12$ at a resonant frequency of $26.8 \mathrm{GHz}$ when one switch is $\mathrm{ON}$ and other switch is OFF. Similarly, Figure 11 shows an improvement of $15.45 \%$ in $\mathrm{S} 12$ at a resonant frequency of 28.2 $\mathrm{GHz}$ when both switches are $\mathrm{ON}$.

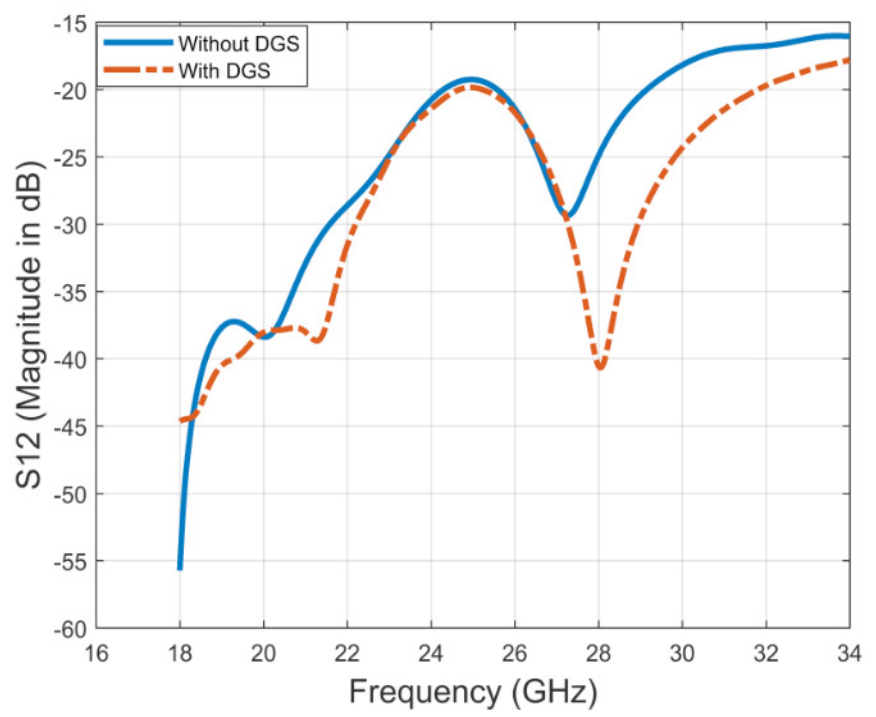

Figure 9: Mutual coupling between two elements by turning OFF both switches. 


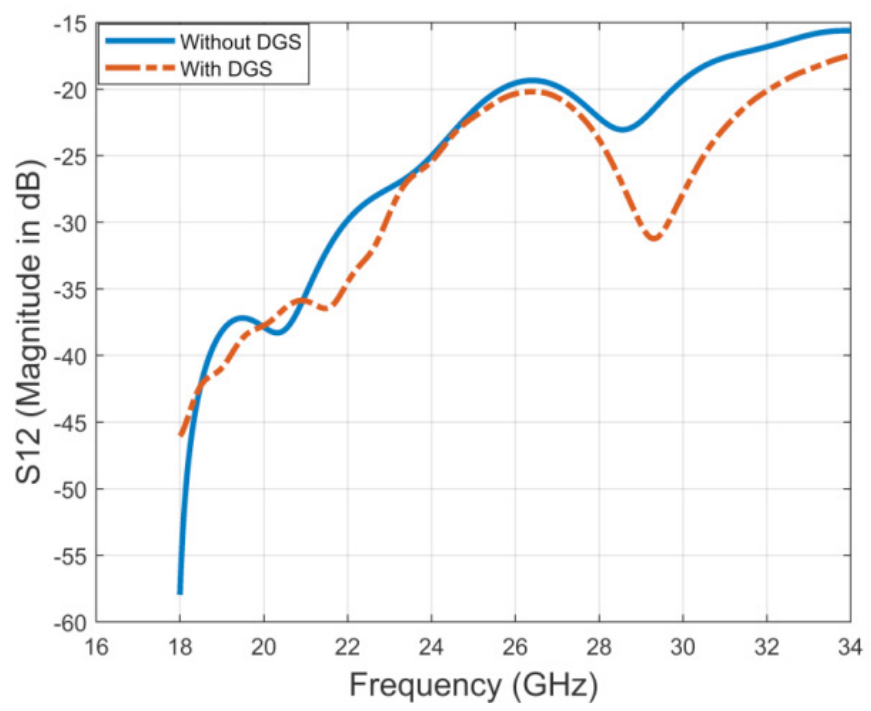

Figure 10: Mutual coupling between two elements by turning one switch $\mathrm{OFF}$ and one ON.

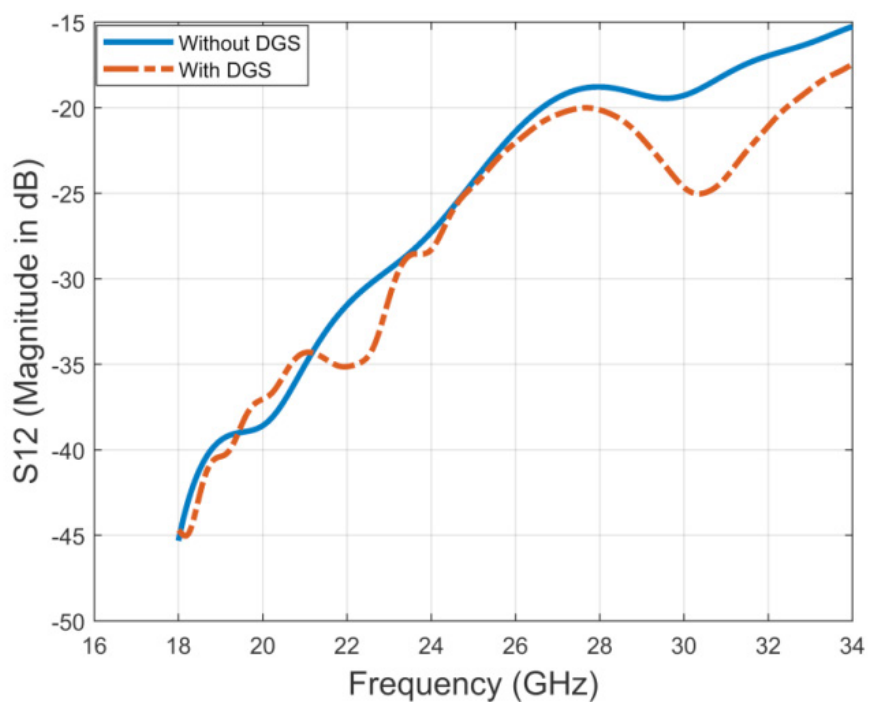

Figure 11: Mutual coupling between two elements by turning $O N$ both switches.

The simulated radiation patterns of proposed antenna array when different portions of array are excited are shown in Figure 12. The main beam is shifted depending on which direction array is excited. In this way, main beam can be steered in any required direction for the best reception of the signal.

The use of eight elements in each array has increased the gain up to $13 \mathrm{~dB}$ and directivity up to $14 \mathrm{~dB}$. Maximum gain versus frequency and maximum directivity versus frequency plots for different number of array elements are given in Figures 13 and 14 respectively. We have shown results for the case when both switches are ON. For other switch combinations these results are almost same.

June 2020 | Volume 39 | Issue 1 | Page 74
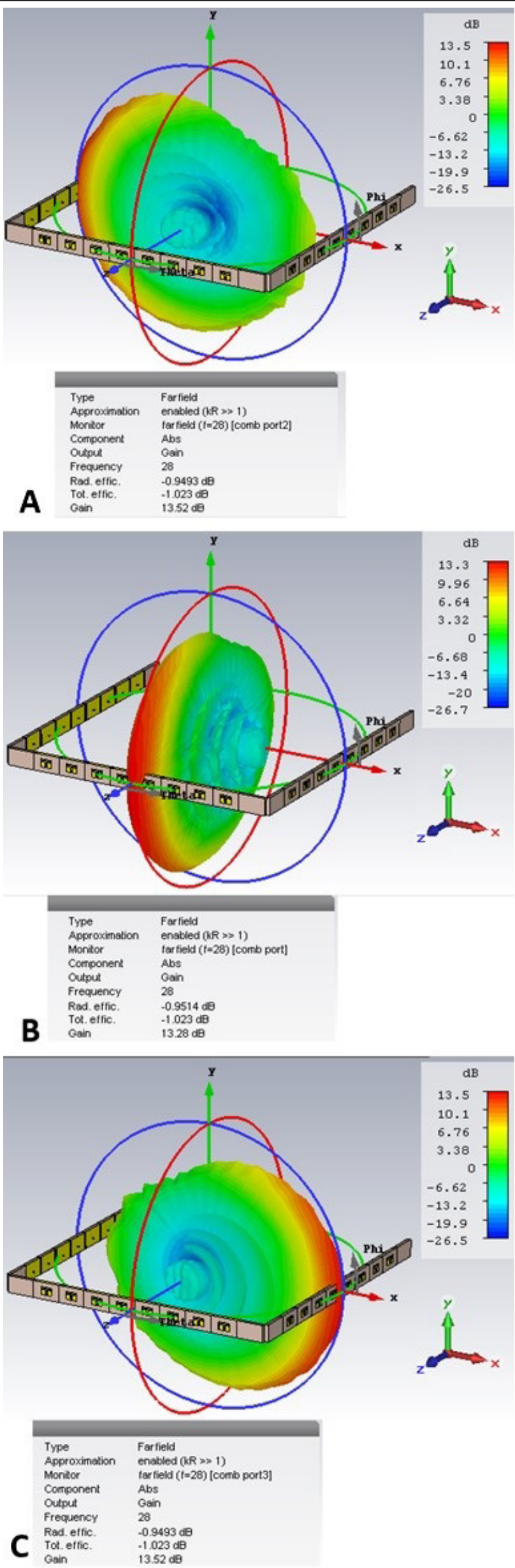

Figure 12: Simulated Radiation pattern; (a) Only Array-1 excited; (b) Only Array-2 excited; (c) Only Array-3 excited. 


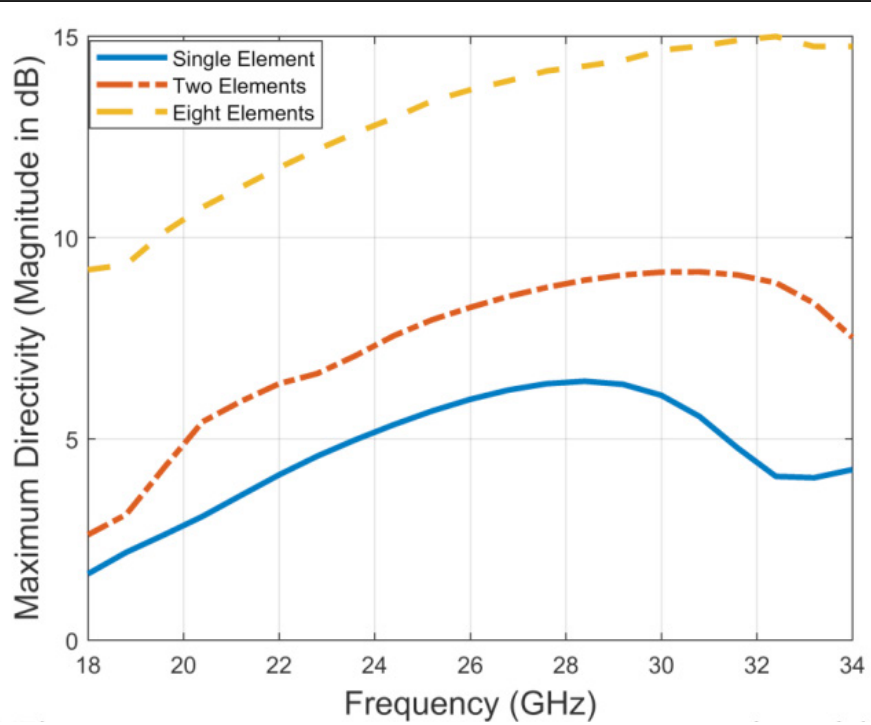

Figure 13: Maximum Gain vs Frequency.

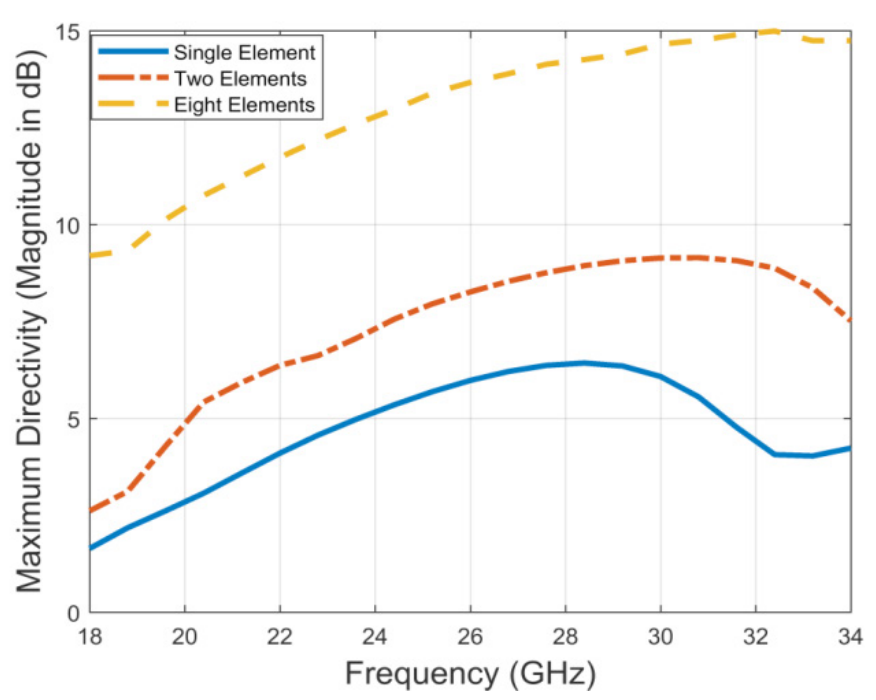

Figure 14: Maximum Directivity vs Frequency.

\section{Conclusions and Recommendations}

In our study, we proposed a beam steerable and frequency reconfigurable antenna for $5 \mathrm{G}$ technology using antenna arrays. The antenna operated at $26 \mathrm{GHz}$ band. The requirements of a $5 \mathrm{G}$ system was fulfilled by using three arrays, each having 8 elements, located at three different locations in a mobile phone. One array was energized at a time in order to direct the main beam in the required direction. By energizing the second array, main beam was shifted to the other direction. In this way, the main beam was steered in any required direction achieving a directivity of $14 \mathrm{~dB}$ and gain of $13 \mathrm{~dB}$. In addition, in each antenna element of the array, there was a slot consisting of two switches. By using different combinations of these switches, resonance frequency was shifted. These switches were adjusted so as to cover an overall bandwidth of 5.19 $\mathrm{GHz}$ (i.e., 24.11 to $29.30 \mathrm{GHz}$ ). An overall reduction of $15.45 \%$ was achieved in mutual coupling by using a DGS. In order to adjust the antenna array at the edges of the mobile phone, each element was fed using a capacitive feeding method which reduced its length.

\section{Novelty Statement}

The novelty lies in the design and location/placement of the antenna array inside the cell phone for increased coverage using beam steering method. The proposed technique of frequency reconfigurability has improved bandwidth up to $5.29 \mathrm{GHz}$.

\section{Conflict of interest}

The author has declared no conflict of interest.

\section{References}

Abirami,M.,2017.A review of patch antenna design for 5G. IEEE International Conference on Electrical,Instrumentation and Communication Engineering (ICEICE). https://doi. org/10.1109/ICEICE.2017.8191842

Agiwal, M., A. Roy and N. Saxena. 2016. Next generation $5 \mathrm{G}$ wireless networks: A comprehensive survey. IEEE Commun. Surv. Tutorials, 18(3): 1617-1655. https://doi. org/10.1109/COMST.2016.2532458

Agiwal, Mamta, N. Saxena and A. Roy. 2019. Towards connected living: $5 \mathrm{G}$ enabled internet of things (iot). IETE Tech. Rev., 36(2): 190220. https://doi.org/10.1080/02564602.2018.1 444516

Aragon-Zavala, A., 2008. Antennas and propagation for wireless communication systems. John Wiley and Sons.

Baruah, R. and N.S. Bhattacharyya. 2017. A frequency reconfigurable antenna with consistent radiation characteristics. International Conference on Innovations in Electronics, Signal Processing and Communication (IESC). https:// doi.org/10.1109/IESPC.2017.8071887

Ezhilarasan, E. and M. Dinakaran. 2017. A review on mobile technologies: $3 \mathrm{G}, 4 \mathrm{G}$ and $5 \mathrm{G}$. Second International Conference on Recent Trends and Challenges in Computational Models (ICRTCCM). ICRTCCM.2017.90

Han, S., C.-L.I.Z. Xu and C. Rowell. 2015. Large-scale antenna systems with hybrid analog and digital beamforming for 
millimeter wave 5G. IEEE Commun. Mag., 53(1): 186-194. https://doi.org/10.1109/ MCOM.2015.7010533

Hossain, E. and M. Hasan. 2015. 5G cellular: key enabling technologies and research challenges. IEEE Instrum. Meas. Mag., 18(3): 11-21. https://doi.org/10.1109/ MIM.2015.7108393

Hur, S., T. Kim, D.J. Love, J.V. Krogmeier, T.A. Thomas and A. Ghosh. 2013. Millimeter wave beamforming for wireless backhaul and access in small cell networks. IEEE Trans. Commun., 61(10): 4391-4403. https://doi.org/10.1109/ TCOMM.2013.090513.120848

Ikram, M., E. Al Abbas, N. Nguyen-Trong, K.H. Sayidmarie and A. Abbosh. 2019. Integrated frequency-reconfigurable slot antenna and connected slot antenna array for $4 \mathrm{G}$ and $5 \mathrm{G}$ mobile handsets. IEEE Trans. Antennas Propag., 67(12): 7225-7233. https://doi. org/10.1109/TAP.2019.2930119

Jenath, M. and V. Nagarajan. 2017. Review on frequency reconfigurable antenna for wireless applications. International Conference on Communication and Signal Processing (ICCSP). https://doi.org/10.1109/ ICCSP.2017.8286815

Khandelwal, M.K., B.K. Kanaujia and S. Kumar. 2017.Defected ground structure: Fundamentals, analysis, and applications in modern wireless trends. Int. J. Antennas Propag., 2017: 1-22. https://doi.org/10.1155/2017/2018527

Nayak, B.S., T. Fickenscher and R.K. Mishra. 2012. Design of beam steerable antenna operating at $2.8 \mathrm{GHz}$. Loughborough Antennas and Propagation Conference (LAPC). https://doi. org/10.1109/LAPC.2012.6403051

Niu, Y., Y.Li, D. Jin, L. Su and A.V. Vasilakos. 2015. A survey of millimeter wave communications (mmWave) for 5G: opportunities and challenges. Wireless Networks, 21(8): 26572676. https://doi.org/10.1007/s11276-0150942-z

Ojaroudi-Parchin, N., H.J. Basherlou, Y.I. Al-Yasir and R.A. Abd-Alhameed. 2020. A design of antenna array with improved performance for future smart phones. Prog. Electromagnet. Res., 101: 1-12. https://doi.org/10.2528/ PIERC20012003

Pal, A., A. Mehta, D. Mirshekar-Syahkal, P. Deo and H. Nakano. 2014. Dual-band low-profile capacitively coupled beam-steerable squareloop antenna. IEEE Trans. Antennas Propagat., 62(3): 1204-1211. https://doi.org/10.1109/ TAP.2013.2294866

Rappaport, S. Theodore, S. Sun, R. Mayzus, H. Zhao, Y. Azar, K. Wang, N. George, J.K. Wong, S.M. Samimi and F. Gutierrez. 2013. Millimeter wave mobile communications for $5 \mathrm{G}$ cellular: It will work! IEEE access 1.1 pp. 335-349. https:// doi.org/10.1109/ACCESS.2013.2260813

Salgare, S. Dhanashri and S.R. Mahadik. 2015. A review of defected ground structure for microstrip antennas. Int. Res. J. Eng. Technol., 2(6): 150-154.

Srinivasan, C.R., B. Rajesh, P. Saikalyan, K. Premsagar and E.S. Yadav. 2019. A review on the different types of Internet of Things (IoT). J. Adv. Res. Dyn. Contr. Syst., 11(10): 154-158.

Varsha, J. and M. Sumi. 2016. A novel pattern and frequency reconfigurable antenna. International Conference on Inventive Computation Technologies (ICICT). https:// doi.org/10.1109/INVENTIVE.2016.7830118

Wei, K., J.-Y. Li, L. Wang, Z.-J. Xing and R. Xu. 2016. Mutual coupling reduction by novel fractal defected ground structure bandgap filter. IEEE Trans. Antennas Propag., 64(10): 4328-4335. https://doi.org/10.1109/TAP.2016.2591058

Zadehparizi, F. and S. Jam. 2018. Increasing reliability of frequency reconfigurable antennas. IEEE Antennas Wirel. Propag. Lett., 17(5): 920-923. https://doi.org/10.1109/ LAWP.2018.2823688

Zhang, W., A. Pal, A. Mehta and D. MirshekarSyahkal. 2017. Low-Pofile beam-steerable microstrip antenna with metamaterial. IEEE International Symposium on Antennas and Propagation and USNC/URSI National Radio Science Meeting. https://doi.org/10.1109/ APUSNCURSINRSM.2017.8073214 